\title{
Land biosphere dynamics during the present and the last interglacials
}

TIM BrÜChER AND VICTOR BRovkIN

Max Planck Institute for Meteorology, Hamburg, Germany; tim.bruecher@zmaw.de

\begin{abstract}
Snapshot simulations are obtained for the preindustrial, the mid-Holocene and the last interglacial time periods characterized by different atmospheric $\mathrm{CO}_{2}$ concentrations and orbital forcing. We evaluate the natural variability of vegetation cover, land carbon storage, and fire activity using a coupled climate-carbon cycle model.
\end{abstract}

D uring the last eight glacial-interglacial cycles, atmospheric $\mathrm{CO}_{2}$ concentration has fluctuated between glacial levels of about $180 \mathrm{ppm}$ and interglacial levels of up to about $300 \mathrm{ppm}$. These $\mathrm{CO}_{2}$ concentration changes appear to be closely linked to Antarctic surface temperature as inferred from ice cores (e.g. Luethi et al. 2008). Several physical and biogeochemical mechanisms responsible for this link have been identified, including changes in sea surface temperatures and deep water formation, marine productivity, $\mathrm{CaCO}_{3}$ accumulation, terrestrial productivity, and weathering. Quantification of their relative roles is under active investigation (e.g. Brovkin et al. 2012). Recently, focus in the paleo-carbon research community has shifted towards the link between surface temperature and $\mathrm{CO}_{2}$ concentration during warm periods, including Quaternary interglacial periods.
Over the penultimate deglaciation, $\mathrm{CO}_{2}$ concentration rapidly increased from $180 \mathrm{ppm}$ to $290 \mathrm{ppm}$ at $128 \mathrm{ka} \mathrm{BP}$, and then stabilized between 270 and 280 ppm for more than $10 \mathrm{ka}$ (Lourantou et al. 2010) over the last interglacial (LIG). At the onset of the Holocene (ca. 12 ka BP), $\mathrm{CO}_{2}$ concentration was about 265 ppm and reached a minimum of 260 ppm by 7 ka BP. Thereafter, $\mathrm{CO}_{2}$ concentration steadily increased by $20 \mathrm{ppm}$ to the preindustrial level of 280 ppm (Elsig et al. 2009).

To date it is unclear what mechanisms drive atmospheric $\mathrm{CO}_{2}$ concentration trends during interglacial periods. While the majority of climate-carbon cycle model simulations (e.g. Elsig et al. 2009; Joos et al. 2004; Kleinen et al. 2010; Menviel and Joos 2012; Ridgwell et al. 2003) agree that the ocean was the main source of carbon entering the atmosphere, the impact of land carbon changes on atmospheric $\mathrm{CO}_{2}$ concentration is less clear. To understand the role of the land biosphere on atmospheric $\mathrm{CO}_{2}$ concentration changes during the present and the last interglacials, we have used the new climate-carbon cycle model CLIMBER-JSBACH, which is the asynchronously coupled Earth System Model of Intermediate Complexity CLIMBER-2 (Ganopolski et al. 2001) and the land component JSBACH of the Max-Planck Earth System Model described by Raddatz et al. (2007). The models are coupled as follows: After one year of climate-ocean simulation by CLIMBER-2 the atmospheric $\mathrm{CO}_{2}$ concentration, and anomalies of monthly precipitation, temperature, and radiation fields are fed to the land component JSBACH. Given these boundary conditions, JSBACH simulates the new carbon allocation and calculates the carbon flux to the atmosphere, which is fed back to the climate model for the next year of simulation. This model setup

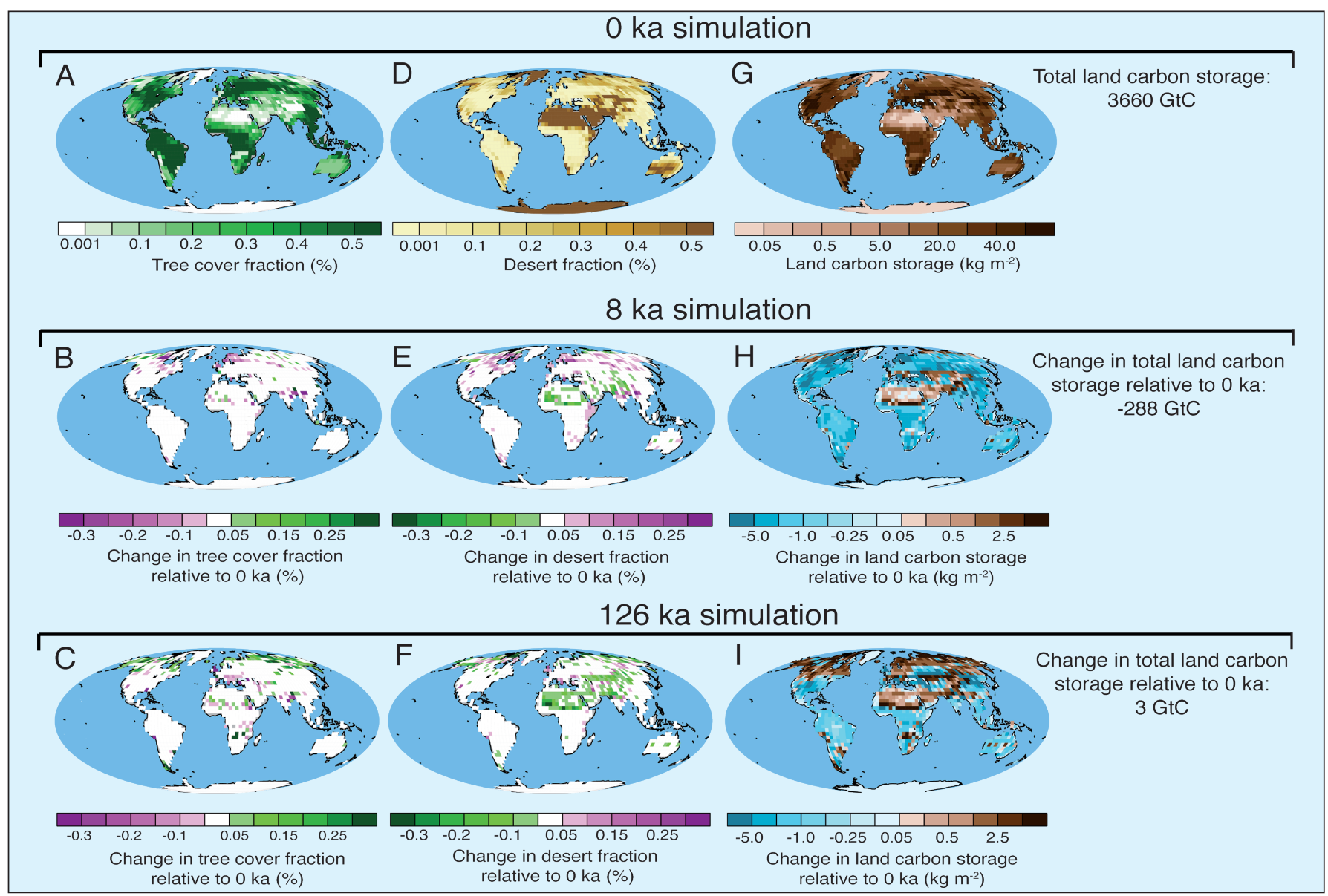

Figure 1: Modeled vegetation and land carbon storage ( $\left.\mathrm{kg} \mathrm{m}^{-2}\right)$ for preindustrial climate: $0 \mathrm{ka} B P(\boldsymbol{A}, \boldsymbol{D}, \boldsymbol{G})$, mid-Holocene: $8 \mathrm{ka} B P(\boldsymbol{B}, \boldsymbol{E}, \boldsymbol{H})$, and the LIG: $126 \mathrm{ka} B P(\boldsymbol{C}, \boldsymbol{F}, \boldsymbol{I})$ Shown are absolute values for preindustrial climate and interglacial anomalies for tree cover fraction (left), desert fraction (middle), and the total land carbon storage (GtC; right). 


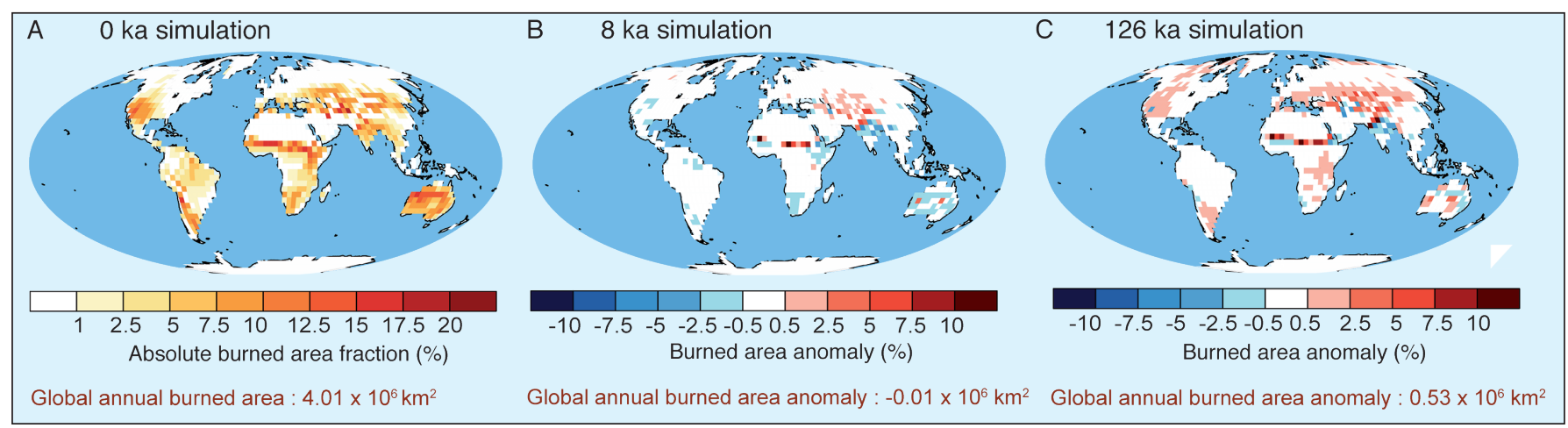

Figure 2: Simulated burned area fraction for $(\boldsymbol{A})$ preindustrial climate. Simulated burned area anomalies for $(\boldsymbol{B})$ mid-Holocene and $(\boldsymbol{C})$ the $L / G$. Global annual values are shown below each plot.

ensures that the highly resolved land carbon processes are retained whilst maintaining an adequate computational speed of the climate and ocean carbon cycle model.

We performed three model simulations forced to equilibrium for preindustrial (0 ka $\mathrm{BP})$, mid-Holocene (8 ka BP) and LIG (126 ka BP) time slices. The Earth's orbital parameters and atmospheric $\mathrm{CO}_{2}$ concentrations were prescribed accordingly. Atmospheric $\mathrm{CO}_{2}$ levels were derived from ice core reconstructions with values of $280 \mathrm{ppm}, 260 \mathrm{ppm}$, and $275 \mathrm{ppm}$ for the preindustrial, midHolocene and LIG simulations, respectively. Additionally, we ran another mid-Holocene simulation with an atmospheric $\mathrm{CO}_{2}$ level of 280 ppm.

\section{Changes in vegetation and land carbon storage}

In response to the mid-Holocene and LIG forcings, the boreal forest expands in the northern high latitudes (Fig. $1 A-C$ ) while West Africa and parts of Asia become less arid, greener, and cooler due to intensified monsoon systems (Fig. 1D-F). The two regions are associated with precipitation rates up to four times higher under the LIG and mid-Holocene forcings compared with the precipitation rate simulated under preindustrial conditions (variables not shown here). These vegetation and climate changes are in general agreement with pollen-based reconstructions and other model studies (e.g. Jolly et al. 1998).

The integrated land carbon storage change for both interglacial time slices resemble similar anomaly patterns, but differ in their magnitude. The dominant zones where a gain in land carbon storage can be identified are within the African and Asian monsoon regions and the boreal forest (Fig. $1 \mathrm{H}-\mathrm{I})$. Due to a lower atmospheric $\mathrm{CO}_{2}$ level at $8 \mathrm{ka} \mathrm{BP}$ compared with preindustrial $\mathrm{CO}_{2^{\prime}}$ fertilization causes a reduction of total carbon storage. This effect is larger than the effect from climate changes. However, the net result from greenhouse gas and orbital forcing changes in the additional simulation for the mid-Holocene at $280 \mathrm{ppm}$ shows that the biomass carbon is approximately 5 Gt higher than the carbon stored during the LIG.

\section{The role of fire activity in warmer climates}

A simple windthrow (uprooting and breaking of trees due to wind) and fire scheme are implemented to simulate vegetation disturbances within JSBACH, which both affect the carbon cycle. For preindustrial climate conditions, the model simulates about $4 \times 10^{6} \mathrm{~km}^{2}$ burned area each year with hotspots in Africa, Australia, and Southwest America (Fig. 2A). Mid-Holocene and LIG burned area anomalies show higher fire activity over the Sahel and the Tibetan plateau (Fig. 2B-C). Globally, however, the total midHolocene burned area is similar to that of the preindustrial, whereas the total burned area fraction is $0.5 \times 10^{6} \mathrm{~km}^{2} \mathrm{yr}^{-1}$ higher under LIG conditions. Nevertheless, an elevated (280 ppm) atmospheric $\mathrm{CO}_{2}$ mid-Holocene simulation (not shown) results in a burned area similar to the LIG. This increase in total burned area fraction compared with the standard mid-Holocene simulation can be attributed to increased fuel availability (i.e. tree growth) leading to higher fire activity.

The carbon emissions associated with fire activity are $2.5 \mathrm{Gt}_{\mathrm{yr}}{ }^{-1}$ for preindustrial conditions. In comparison, the carbon emissions associated with fire activity in the LIG simulation are $10 \%$ higher and there is a $25 \%$ increase in burned area extent, as the carbon stored in biomass is reduced (not shown). As for the mid-Holocene simulation, there is a decrease of $7 \%$ compared with the preindustrial conditions despite similar burned areas. Since charcoal-based reconstructions (Power et al. 2008) show an opposite trend during the Holocene with increasing fire intensity since the Last Glacial Maximum, it should be noted that the model setup does not account for land use changes and the simulations do not include the large increase in fire activity observed during the last century when calculating the burned area extent. Furthermore, the reconstructions are based on data from individual locations and do not necessarily correspond to the $2 \mathrm{D}$ fields from the model.

\section{Summary}

We performed time slice experiments under preindustrial, mid-Holocene, and LIG conditions to analyze the changes in vegetation distribution, carbon storage on land, and disturbance processes under perturbed climate forcings. The impacts from secondorder processes, such as natural fire activity on carbon emissions, are found to be of the same magnitude (2.5 Gt $\left.\mathrm{yr}^{-1}\right)$ as the simulated anomaly in the total land carbon storage between LIG and preindustrial climate (3 Gt $\mathrm{yr}^{-1}$ ). A recent study, also with JSBACH, showed that during the last 6000 years the boreal wetland $\mathrm{CH}_{4}$ emissions increased by 2 Tg yr $^{-1}$ (Schuldt et al. 2012). This highlights the importance of including these additional processes in models. Using a model setup such as CLIMBER-JSBACH makes it possible to resolve heterogeneous and subscale processes within the biosphere and still be able to perform climate simulations on long time scales.

As part of the Past4Future framework, research groups have also performed transient past interglacial simulations to understand the underlying dynamics behind carbon storage with results compared to available paleodata. Furthermore, we are investigating the impact of different land use scenarios during the Holocene, with the aim of providing an uncertainty range in terms of human impact on Holocene climate and $\mathrm{CO}_{2}$ dynamics.

\section{Selected references}

Full reference list online under:

http://www.pages-igbp.org/products/newsletters/ref2013_1.pdf

Brovkin V et al. (2012) Climate of the Past 8: 251-264

Elsig J et al. (2009) Nature 461: 507-510

Lourantou A et al. (2010) Quaternary Science Reviews 29: 1983-1992

Power MJ et al. (2008) Climate Dynamics 30: 887-907

Schuldt RJ et al. (2012) Biogeosciences Discussions 9: 12667-12710 